\title{
A Case Report of a Patient with a Rare and Aggressive Plasma Cell Leukemia
}

\author{
Ugroseno Yudho Bintoro, Putu Niken Amrita, Raharjo Budiono, Made Putra Sedana and Ami \\ Ashariati \\ ${ }^{I}$ Division of Hematology and Medical Oncology, Department of Internal Medicine, Faculty of Medicine, University of \\ Airlangga, Dr. Soetomo General Hospital, Jl. Prof dr. Moestopo 47 Surabaya 60132, Indonesia \\ nikenamrita@gmail.com,apji@fk.unair.ac.id
}

\begin{abstract}
Keywords: Plasma cell leukemia, plasma cell malignancy, poor prognosis
Abstract: Plasma cell leukemia (PCL) is the most aggressive form of the plasma cell dyscrasias. This rare disease remains a challenge in regard to diagnosis and treatment due to its rarity and aggressive nature. PCL is a rare plasma cell malignancy with poor prognosis. There is still limited literature and numerous trials on this disease treatment. Novel agents and autologous stem cell transplant can be given to prolong survival and increase life quality. Reports on PCL is very important for references regarding future treatments.
\end{abstract}

\section{INTRODUCTION}

Plasma cell leukemia (PCL) is the most aggressive form of plasma cell dyscrasias. Plasma cell leukemia can either originate de novo (primary PCL) or as a secondary leukemic transformation of $\mathrm{MM}$ (secondary PCL) (Kyle, Maldonado, \& Bayrd, 1974). Primary PCL has distinct biological, clinical and laboratory features than multiple myeloma. The diagnosis is based on hematological features including the presence of $>2.10^{9} / \mathrm{L}$ peripheral blood plasma cells or plasmacytosis of more than $20 \%$ of the differential white cell count (International Myeloma Working Group, 2013). Plasma cell leukemia is a rare disease as its prevalence is less than 1 case in 1 million population. In the United States, the incidence is approximately 0.02 to 0.03 cases per 100,000 population, less than $0.2 \%$ of all leukemia cases from 1997 to 2002 (Yamamoto \& Goodman, 2008).

The PCL outcome has improved along with the introduction of the novel agent, bortezomib, and autologous stem cell transplants. The prognosis of this disease is poor as the average survival is 7 months using standard chemotherapy and supportive treatment (van de Donk, Lokhorst, Anderson, \& Richardson, 2012). We report a case of a PCL patient in its aggressive course, the diagnosis, and management in a tertiary hospital in a developing country.

\section{CASE PRESENTATION}

A 50-year-old man came with general weakness for 1 week before admission. The patient also had breathing shortness and palpitation complaints. $\mathrm{He}$ felt that he lost his medial right visual field. He had pain complaints in his right shoulder. Physical examination revealed pallor, conjunctival bleeding, gum bleeding and petechiae in the body and extremities. There were painless skin lesions on the patient's chest, arm and legs, sized $0.5-1 \mathrm{~cm}$. There was also lymph node enlargement in the left neck, size $3 \mathrm{~cm}$, which was non-tender. Abdominal examination revealed grade-II splenomegaly.

Laboratory results showed hemoglobin $9.4 \mathrm{~g} / \mathrm{dL}$, leucocytes 38,720/uL, thrombocytes 34,000/uL, LED 103. MCV 89.9; MCH 29.7; MCHC 33.1; differential eosinophil count 0; Basophil 1; neutrophil segment 10 ; stab 0 ; lymphocytes 51 ; monocytes 38. Creatinine serum $1.0 \mathrm{mg} / \mathrm{dL}$ and calcium serum $9.4 \mathrm{mg} / \mathrm{dL}$.

Peripheral blood smear: erythrocyte: hypochromic anisocytosis system, leucocyte: no blast plasma cell 60\%. Thrombopoiesis activity decreased. Plasma absolute 14,220/ $\mu$ L. Blood viscosity 7.5; and plasma viscosity 4.3

A serum electrophoresis test showed a discrete band at the gamma globulin level. Chest X-ray showed cardiomegaly. The bone survey showed no osteolytic lesion in the calvaria, humerus, radius ulna, femur, pelvic bone, scapula and clavicle. Bone marrow aspiration showed plasma cell $40 \%$. 
Immunophenotyping from peripheral blood showed the presence of circulating monoclonal plasma cell with CD 38+, CD 138+, CD56-. Beta-2 macroglobulin was 20 (normal range 0.85-1.62). The patient was diagnosed with plasma cell leukemia.

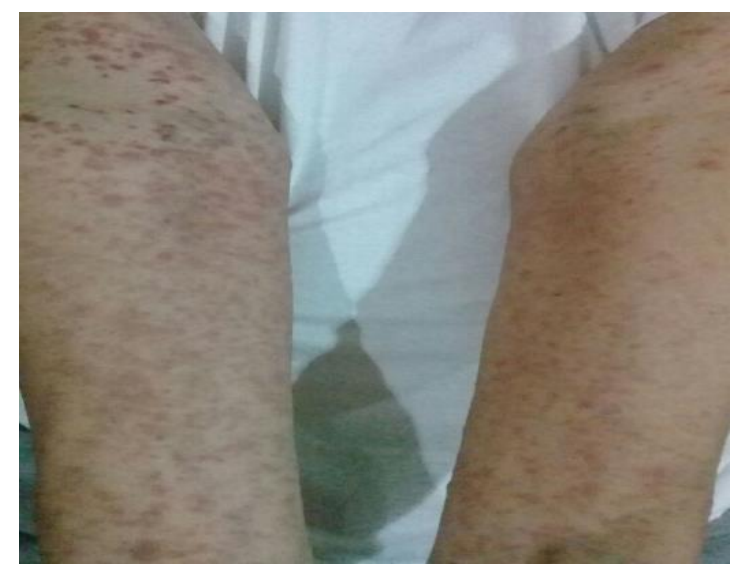

Figure 1: Cutaneous Manifestation of Plasma Cell Leukemia.

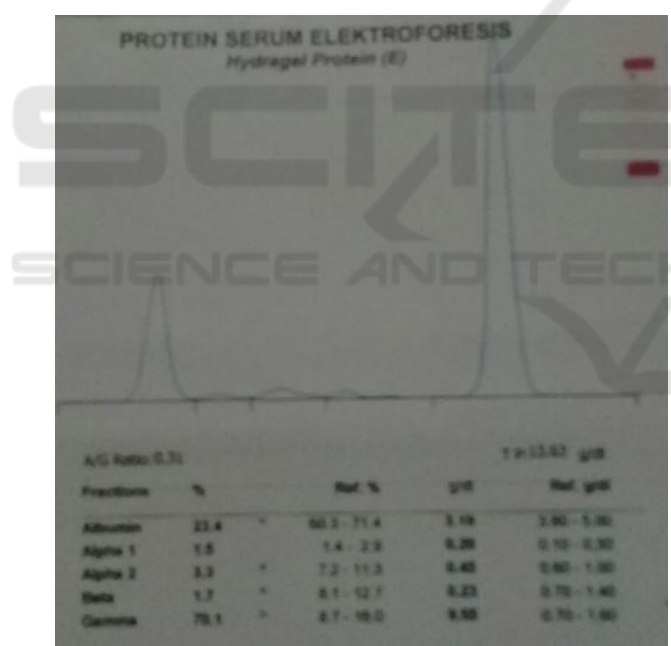

Figure 2: Serum Electrophoresis Shows a Band at the Gamma Globulin Level.

The patient was given supportive treatment of a high-calorie diet of 2,100 kcal, IV normal saline of $1,000 \mathrm{ml} /$ day and a packed red cell transfusion to achieve hemoglobin level > $10 \mathrm{~g} / \mathrm{dL}$. He also received paracetamol for his fever and back pain and pamidronate infusion.

Treatment with bortezomib $1.3 \mathrm{mg} / \mathrm{m}^{2}$ was initiated and scheduled for day 1, 4, 8, 11 with 10day rest. The evaluation after 1 cycle of bortezomib showed decreased protein electrophorese, although it was still abnormal. We decided to use a 3-drug regimen and started treatment with VCD (bortezomib, cyclophosphamide, dexamethasone). After 2 cycles of VCD, the patient's pain complaint decreased and skin lesions subsided. Peripheral blood hemoglobin $10.4 \mathrm{~g} / \mathrm{dL}$, leucocytes $22,720 / \mathrm{uL}$, thrombocytes 83,000/uL. The peripheral blood smear showed that plasma cell decreased by $20 \%$. Beta-2 macroglobulin after the first cycle of VCD was 9.2 (normal range $0.85-1.62$ ). We planned to continue the regimen to 4 cycles. After primary treatment, we planned to continue to peripheral blood autologous stem cell transplantation (ASCT). Unfortunately, 3 weeks after the second regimen, the patient had pneumonia and sepsis. The patient passed away despite all the supportive treatment given.

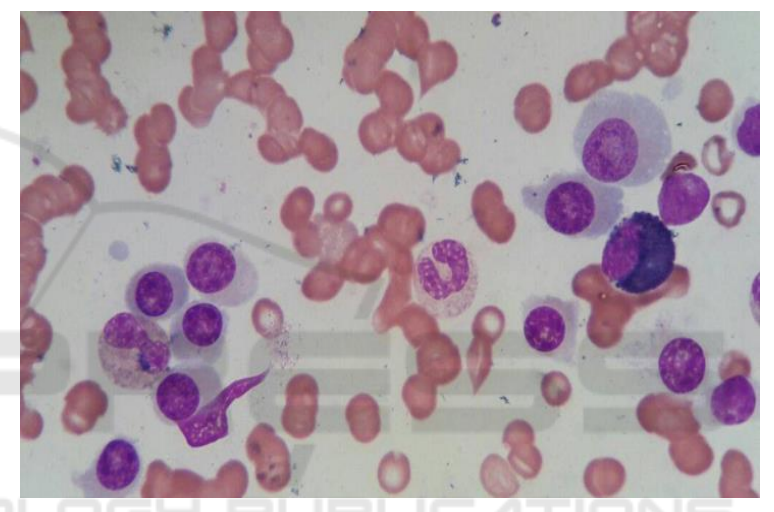

Figure 3: Peripheral Blood Smear Showing Increased Plasma Cells.

\section{DISCUSSION}

Plasma cell leukemia is a rare disease. It is characterized by circulating plasma cells (PCs) of more than $2 \times 10^{9} / \mathrm{L}$ in peripheral blood and peripheral blood plasmacytosis $>20 \%$ (Kyle et al., 1974). In MM, in the early stages, the transforming long-lived PCs persist in bone marrow for many years. The initial genetic mutation occurs at the preB stage, inside the germ center (GC), before continuing with oncogenic somatic hypermutation. Further mutations will lead to the evolution of monoclonal gammopathy of undetermined significance (MGUS) into smoldering MM (SMM), MM and subsequently an aggressive MM from plasma cell leukemia or MM extramedullary. The PCs' progressiveness will be followed by interaction between tumor cells and components in the microenvironment such as osteoclasts, endothelial 
cells and immune cells. In primary PCL, these genetic abnormalities are already present at the time of diagnosis (van de Donk et al., 2012).

Primary PCL (pPCL) is defined as a malignant PC proliferation that is first diagnosed in the leukemic phase. On the other hand, secondary PCL (sPCL) corresponds to the leukemic transformation of a previously diagnosed $\mathrm{MM}$, probably as a consequence of clonal transformation. Compared to MM, pPCL tends to occur in younger subjects. The average age of pPCL diagnosis is 55, a decade younger than the average age for MM diagnosis (Kyle, 1975).

This disease clinically has an aggressive behavior, with a clinical presentation similar to acute leukemia. The patient often has anemia, leukocytosis, and thrombocytopenia due to marrow PC dyscrasia. Extramedullary involvement, such as splenomegaly and hepatomegaly, commonly occurs in pPCL. Primary PCL patients do not have MM prodromal signs and symptoms, characterized by a higher prevalence of renal insufficiency and elevated ß2 microglobulin. Osteolytic lesions are rarely found in pPCL compared to sPCL (Tiedemann et al., 2008). The most common monoclonal proteins secreted in PCL are $\operatorname{IgG}(33 \%), \operatorname{IgA}(20 \%), \operatorname{IgD}$ (3\%) and $\operatorname{IgE}(1 \%)$. Some patients $(35 \%)$ only produce light chain protein, and less than $10 \%$ are non-secretors. Diagnosis criteria set by the International Myeloma Working Group are:

1. Plasma cells $>2 \times 10^{9} / \mathrm{L}$ in peripheral blood.

2. Plasma cells $>20 \%$ of peripheral blood leukocytes.

3. Primary PCL: presents as de novo leukemia.

4. Secondary PCL: progressing from a preexisting MM (International Myeloma Working Group, 2013).

Peripheral blood examination in pPCL shows circulating tumor cells and leucoerythroblastic in $67 \%$ of patients. Bone marrow biopsy shows extensive BM involvement that disrupts normal hematopoiesis. Some cases show normal plasma cells, while others show lymphoplasmacytoid cells (Johnson et al., 2006).

Immunophenotyping for PC markers is CD38 and CD138, but these do not differ between MM and PCL. The immunophenotyping difference between MM and pPCL are pPCL cells are less positive for CD56, CD71, CD117 and HLA-DR, but more likely express CD20, CD45, CD19, CD27 and CD23 (Pellat-Deceunynck et al., 1998).

Cytogenetic analysis performed by FISH focuses on del (17p13), del (13q), del (1p21), ampl (1q21), t
$(11 ; 14), \mathrm{t}(4 ; 14)$, and t $(14 ; 16)$ (van de Donk et al., 2012). However, pPCL clearly defines high-risk plasma cell disorder; therefore, the importance of additional risk stratification by cytogenetics to guide treatment strategy or predict the outcome is limited. Cytogenetics examination is also limited in Indonesia.

\section{TREATMENT of pPCL}

There is limited literature discussing pPCL management. Due to the disease rarity, there have been no randomized trials exclusively reporting patients with pPCL. Treatment of both pPCL and SPCL, as in Multiple Myeloma, is aimed at prolonging survival and maximizing quality of life as there is no curative treatment. In transplant eligible patients, high-dose therapy with autologous stem cell rescue is currently the most effective therapeutic modality to achieve long-term remission.

Chemotherapy is a principal option for those ineligible for HCT (Albarracin \& Fonseca, 2011). Multi-agent infusional chemotherapy (e.g. vincristine, doxorubicin plus dexamethasone) results in increased but still poor overall survival, approximately 15 to 18 months.

Bortezomib, a proteasome inhibitor in a single institution experience, describes a series of 25 patients with a high response rate in 16 of 18 patients treated with a bortezomib-containing regimen. The overall survival of patients treated with bortezomib is also increased to 28 months compared to 4 months in those who did not receive this treatment (Lebovic et al., 2011).

Several studies have reported a survival benefit of bortezomib; therefore, current treatment uses a 3drug bortezomib-based induction regimen, such as RVD (revlimid, velcade, dexamethasone), PAD (bortezomib, adriamycin, dexamethasone), CVD (cyclophosphamide, bortezomib, dexamethasone) or VTD. This treatment is followed by an autologous transplant for ineligible patients. The Center for International Blood \& Marrow Transplant Research (CIBMTR) reported progression-free survival and overall survival at 3 years of $34 \%$ and $62 \%$, respectively, in 97 patients with pPCL who underwent ASCT. This supports the role of ASCT in transplant-eligible patients and offers an opportunity for relatively prolonged remission (Mahindra et al., 2012). 


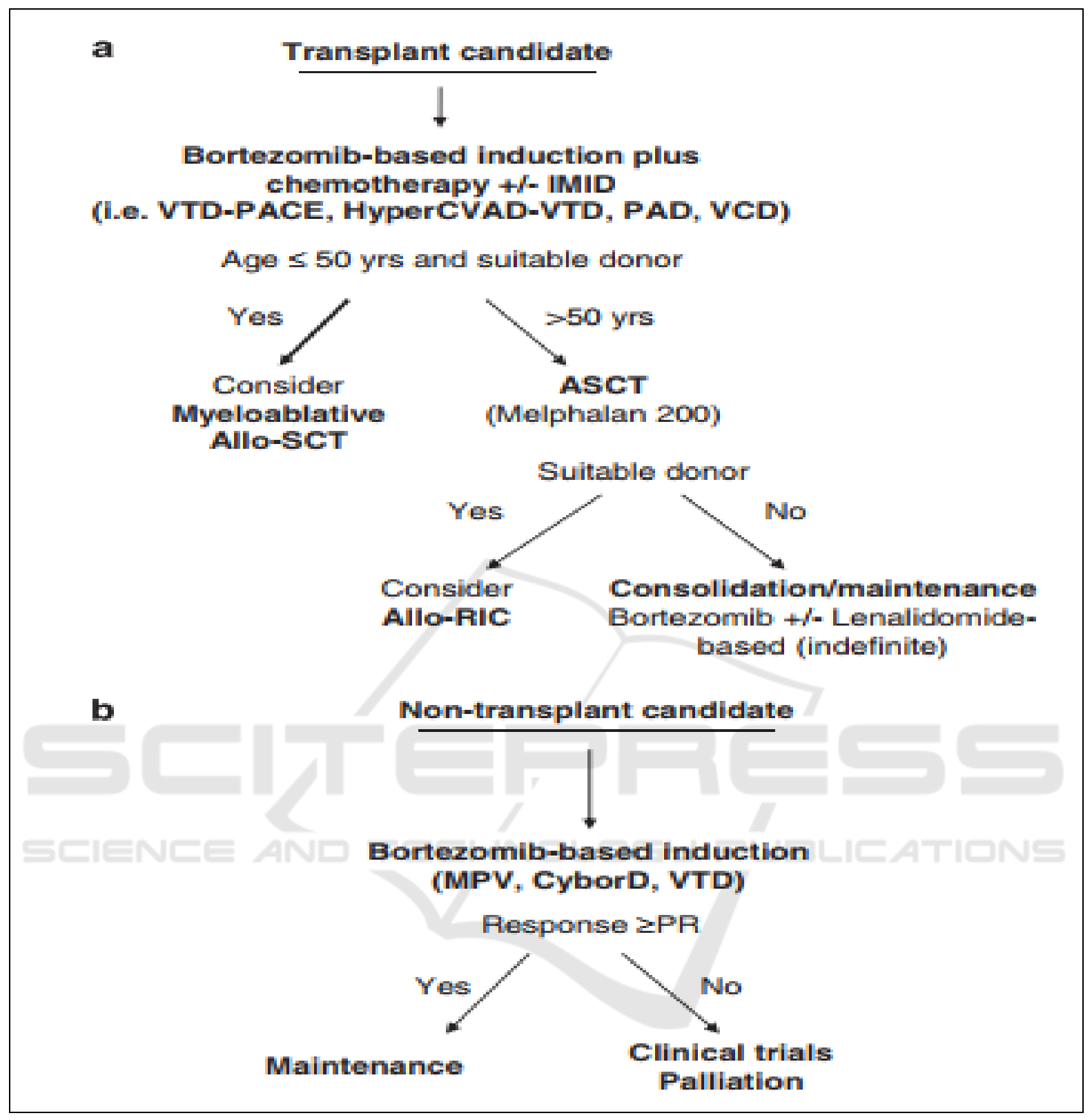

Figure 4: Treatment Algorithm for pPCL (Fernandez de Larrea et al., 2013).

The PCL prognosis is poor as the patient only survives until 7-11 months, with up to $28 \%$ patients passing away within 1 month of diagnosis.

\section{CONCLUSION}

Plasma cell leukemia is a rare plasma cell malignancy with poor prognosis. There is still limited literature and numerous trials on the disease treatment. Novel agents and autologous stem cell transplants can be given to prolong survival and increase quality of life.

\section{REFERENCES}

Albarracin, F., \& Fonseca, R. (2011). Plasma cell leukemia. Blood Rev, 25(3), 107-112. doi: 10.1016/j.blre.2011.01.005 
Fernandez de Larrea, C., Kyle, R. A., Durie, B. G., Ludwig, H., Usmani, S., Vesole, D. H., . . . International Myeloma Working, G. (2013). Plasma cell leukemia: consensus statement on diagnostic requirements, response criteria and treatment recommendations by the International Myeloma Working Group. Leukemia, 27(4), 780-791. doi: 10.1038/leu.2012.336

International Myeloma Working Group. (2013). Plasma Cell Leukemia. Consensus Statement on Diagnostics Requirements, Response Criteria, and Treatment Recommendations by the International Myeloma Working Group (IMWG). . Leukemia, 27(4), 780-791.

Johnson, M. R., Del Carpio-Jayo, D., Lin, P., Giralt, S., Anderlini, P., Champlin, R. E., . . . Bueso-Ramos, C. E. (2006). Primary plasma cell leukemia: morphologic, immunophenotypic, and cytogenetic features of 4 cases treated with chemotherapy and stem cell transplantation. Ann Diagn Pathol, 10(5), 263-268. doi: 10.1016/j.anndiagpath.2005.12.011

Kyle, R. A. (1975). Multiple myeloma: review of 869 cases. Mayo Clin Proc, 50(1), 29-40.

Kyle, R. A., Maldonado, J. E., \& Bayrd, E. D. (1974). Plasma cell leukemia. Report on 17 cases. Arch Intern Med, 133(5), 813-818.

Lebovic, D., Zhang, L., Alsina, M., Nishihori, T., Shain, K. H., Sullivan, D., . . . Baz, R. (2011). Clinical outcomes of patients with plasma cell leukemia in the era of novel therapies and hematopoietic stem cell transplantation strategies: a single-institution experience. Clin Lymphoma Myeloma Leuk, 11(6), 507-511. doi: 10.1016/j.clml.2011.06.010

Mahindra, A., Kalaycio, M. E., Vela-Ojeda, J., Vesole, D. H., Zhang, M. J., Li, P., . . . Hari, P. (2012). Hematopoietic cell transplantation for primary plasma cell leukemia: results from the Center for International Blood and Marrow Transplant Research. Leukemia 26(5), 1091-1097. doi: 10.1038/leu.2011.312

Pellat-Deceunynck, C., Barille, S., Jego, G., Puthier, D., Robillard, N., Pineau, D., . . . Bataille, R. (1998). The absence of CD56 (NCAM) on malignant plasma cells is a hallmark of plasma cell leukemia and of a special subset of multiple myeloma. Leukemia, 12(12), 1977 1982.

Tiedemann, R. E., Gonzalez-Paz, N., Kyle, R. A., Santana-Davila, R., Price-Troska, T., Van Wier, S. A. ... Fonseca, R. (2008). Genetic aberrations and survival in plasma cell leukemia. Leukemia, 22(5), 1044-1052. doi: 10.1038/leu.2008.4

van de Donk, N. W., Lokhorst, H. M., Anderson, K. C., \& Richardson, P. G. (2012). How I treat plasma cell leukemia. Blood, 120(12), 2376-2389. doi: 10.1182/blood-2012-05-408682

Yamamoto, J. F., \& Goodman, M. T. (2008). Patterns of leukemia incidence in the United States by subtype and demographic characteristics, 1997-2002. Cancer Causes Control, 19(4), 379-390. doi: 10.1007/s10552007-9097-2 